\title{
ALS-Associated Ataxin 2 PolyQ Expansions Enhance Stress-Induced Caspase 3 Activation and Increase TDP-43 Pathological Modifications
}

\author{
Michael P. Hart ${ }^{1,2}$ and Aaron D. Gitler ${ }^{1}$ \\ ${ }^{1}$ Department of Genetics, Stanford University School of Medicine, Stanford, California 94305, and 2Neuroscience Graduate Group and Department of Cell \\ and Developmental Biology, Perelman School of Medicine at the University of Pennsylvania, Philadelphia, Pennsylvania 19104
}

\begin{abstract}
Amyotrophic lateral sclerosis (ALS) is a devastating neurodegenerative disease caused by the loss of motor neurons. The degenerating motor neurons of ALS patients are characterized by the accumulation of cytoplasmic inclusions containing phosphorylated and truncated forms of the RNA-binding protein TDP-43. Ataxin 2 intermediate-length polyglutamine (polyQ) expansions were recently identified as a risk factor for ALS; however, the mechanism by which they contribute to disease is unknown. Here, we show that intermediate-length ataxin 2 polyQ expansions enhance stress-induced TDP-43 C-terminal cleavage and phosphorylation in human cells. We also connect intermediate-length ataxin 2 polyQ expansions to the stress-dependent activation of multiple caspases, including caspase 3. Caspase activation is upstream of TDP-43 cleavage and phosphorylation since caspase inhibitors block these pathological modifications. Analysis of the accumulation of activated caspase 3 in motor neurons revealed a striking association with ALS cases harboring ataxin 2 polyQ expansions. These findings indicate that activated caspase 3 defines a new pathological feature of ALS with intermediate-length ataxin 2 polyQ expansions. These results provide mechanistic insight into how ataxin 2 intermediate-length polyQ expansions could contribute to ALS - by enhancing stress-induced TDP-43 pathological modifications via caspase activation. Because longer ataxin 2 polyQ expansions are associated with a different disease, spinocerebellar ataxia 2, these findings help explain how different polyQ expansions in the same protein can have distinct cellular consequences, ultimately resulting in different clinical features. Finally, since caspase inhibitors are effective at reducing TDP-43 pathological modifications, this pathway could be pursued as a therapeutic target in ALS.
\end{abstract}

\section{Introduction}

Amyotrophic lateral sclerosis (ALS) is an adult-onset neurodegenerative disease characterized by motor neuron degeneration, resulting in paralysis and death (Cleveland and Rothstein, 2001). A role for the RNA-binding protein TDP-43 in ALS has emerged. TDP-43 mutations have been identified in some familial and sporadic ALS patients (Da Cruz and Cleveland, 2011), and the degenerating neurons of the majority of ALS patients (almost all nonSOD1 ALS patients) are characterized by abundant ubiquitinated cytoplasmic inclusions containing TDP-43 (Neumann et al., 2006). In addition to cytoplasmic mislocalization and ubiq-

Received Feb. 29, 2012; revised May 8, 2012; accepted May 17, 2012.

Author contributions: M.P.H. and A.D.G. designed research; M.P.H. performed research; M.P.H. and A.D.G. analyzed data; M.P.H. and A.D.G. wrote the paper.

This work was supported by NIH Director's New Innovator Award 1DP20D004417 (A.D.G.) and NIH Grants 1R01NS065317 and 1R01NS073660 (A.D.G.). A.D.G. is a Pew Scholar in the Biomedical Sciences, supported by The Pew Charitable Trusts, and a Rita Allen Foundation Scholar. M.P.H. is supported by an NIH Ruth L. Kirschstein NRSA predoctoral fellowship 5F31NS074848. We thank John Trojanowski and the Center for Neurodegenerative Disease Research at the University of Pennsylvania for sharing ALS patient samples and advice on immunohistochemistry experiments. We thank Min Min Lu and Lan Cheng for help with immunohistochemistry. We thank members of the Gitler laboratory and Nancy Bonini for comments and suggestions on this manuscript and for helpful discussions.

The authors declare no competing financial interests.

Correspondence should be addressed to Aaron D. Gitler, 300 Pasteur Drive, M322 Alway Building, Stanford, CA 94305.E-mail: agitler@stanford.edu.

DOI:10.1523/JNEUROSCI.0996-12.2012

Copyright $\odot 2012$ the authors $\quad 0270-6474 / 12 / 329133-10 \$ 15.00 / 0$ uitination, TDP-43 undergoes disease-specific biochemical modifications. Pathological TDP-43 is phosphorylated (Hasegawa et al., 2008; Neumann et al., 2009), and there is evidence that phosphorylation increases aggregation and toxicity (Kraemer et al., 2010; Brady et al., 2011; Miguel et al., 2011). TDP-43 is also cleaved into various $\mathrm{C}$-terminal fragments, which accumulate in affected neurons and glia (Neumann et al., 2006; Igaz et al., 2008). Once generated, the highly insoluble C-terminal fragments become rapidly phosphorylated and ubiquitinated (Igaz et al., 2009). These fragments might act as seeds for the subsequent aggregation of additional TDP-43, contributing to a pathological cascade resulting in depletion of TDP-43 from the nucleus and accumulation in cytoplasmic inclusions (Pesiridis et al., 2011). Defining mechanisms regulating these modifications will provide insight into pathogenesis and might be points for therapeutic intervention.

Spinocerebellar ataxia type 2 (SCA2) is an autosomal dominant hereditary ataxia (Orr and Zoghbi, 2007) caused by polyglutamine (polyQ) tract expansions in ataxin 2 (Imbert et al., 1996; Pulst et al., 1996; Sanpei et al., 1996; Lorenzetti et al., 1997). The hallmark pathology in SCA2 is the atrophy and loss of Purkinje neurons from the cerebellar cortex, causing deficits in motor coordination that affect gaze, speech, gait, and balance (LastresBecker et al., 2008). In SCA2, motor neurons are also known to degenerate, as in ALS, although these features typically occur later 
than the cerebellar degeneration. However, in select cases, the motor neuron features of SCA2 are prominent enough to mimic an ALS presentation (Infante et al., 2004; Nanetti et al., 2009), indicating potential for clinicopathological overlap between SCA2 and ALS (Fischbeck and Pulst, 2011).

The ataxin 2 polyQ tract length, although variable, is most frequently 22-23Qs, with expansions of $>34$ causing SCA2. Intermediate-length ataxin 2 polyQ expansions (27-33Qs), longer than normal but not past the SCA2 pathogenic range, were recently associated with increased risk for ALS (Elden et al., 2010). Thus, ataxin 2 intermediate-length polyQ expansions appear to be a fairly common genetic risk factor for ALS. What is the mechanism by which intermediate-length ataxin 2 polyQ expansions contribute to ALS pathogenesis? Also, how might long polyQ expansions (>34Qs) cause one disease (SCA2), whereas moderate expansions (27-33Qs) contribute to another disease (ALS)? In other words, what are the functional differences between ataxin 2 with 22Qs (normal), 27-33Qs (ALS risk), and $>34$ Qs (SCA2)? To address these questions and define the mechanism(s) by which ataxin 2 might contribute to ALS, here we have investigated the cellular consequences of ataxin 2 polyQ expansions and their effects on TDP-43.

\section{Materials and Methods}

Plasmids. The ataxin 2 expression vectors (22Q, 31Q, 39Q) are described (Elden et al., 2010).

HEK293T, patient-derived lymphoblast, and BE(2)-M17 cell culture and heat shock. HEK293T cells were cultured in DMEM high-glucose medium supplemented with $10 \%$ fetal bovine serum, penicillin, and streptomycin. Cells were transfected using Fugene 6 Transfection Reagent (Promega) according to the manufacturer's protocol and incubated for $48 \mathrm{~h}$ to allow protein expression. Lymphoblast cell lines were obtained from patients with ALS with normal ataxin 2 (3 lines, 22Q) or with polyQ-expanded ataxin $2(27 \mathrm{Q}, 29 \mathrm{Q}, 31 \mathrm{Q}, 32 \mathrm{Q})$ or with SCA2 (40Q) (Coriell). Lymphoblast cells lines were cultured in RPMI 1640 medium supplemented with $2 \mathrm{~mm}$ L-glutamine, 10\% fetal bovine serum, penicillin, and streptomycin. Where indicated, cells were treated with $30 \mu \mathrm{M}$ Z-DEVD-FMK (BD Biosciences) for $24 \mathrm{~h}$, or with $1 \mu \mathrm{M}$ staurosporine (Sigma) for 3 h. BE(2)-M17 neuroblastoma cells (M17 cells) were cultured in a 1:1 mixture of Eagle's MEM and F12 medium supplemented with $10 \%$ fetal bovine serum, penicillin, and streptomycin. M17 cells were transfected using Fugene 6 Transfection Reagent (Promega) according to the manufacturer's protocol and incubated for $48 \mathrm{~h}$ to allow protein expression. M17 cells were then differentiated for $5 \mathrm{~d}$ in 1:1 MEM and F12 medium supplemented with $2 \%$ fetal bovine serum, penicillin, and streptomycin and $10 \mu \mathrm{m}$ retinoic acid (Sigma).

HEK293T, lymphoblast cell lines, or M17 cells were incubated at $37^{\circ} \mathrm{C}$ for $1 \mathrm{~h}$ as a control or heat shocked at $42^{\circ} \mathrm{C}$ for $1 \mathrm{~h}$, then washed $1 \times$ in PBS, and lysed in NP-40 lysis buffer ( $150 \mathrm{~mm} \mathrm{NaCl}, 50 \mathrm{~mm}$ Tris, pH 8.0, $1 \% \mathrm{NP}-40$, and protease inhibitor). Lysates were cleared by centrifugation at 10,000 RPM for $10 \mathrm{~min}$ at $4^{\circ} \mathrm{C}$, and the supernatant was kept as the soluble fraction. Pellets were washed $1 \times$ in NP-40 lysis buffer, then resuspended in urea buffer ( $7 \mathrm{~m}$ urea, $2 \mathrm{~m}$ thiourea, $4 \%$ CHAPS, $30 \mathrm{~mm}$ TRIS, $\mathrm{pH}$ 8.8) and sonicated for $2 \mathrm{~s}$ to make the insoluble fraction. Both soluble and insoluble fractions were resuspended in $4 \times$ sample buffer (40\% glycerol, $240 \mathrm{~mm}$ Tris HCl, pH 6.8, 8\% SDS, 0.04\% bromophenol blue, $5 \% \beta$-mercaptoethanol). Where indicated, TDP-43 was dephosphorylated by dialysis ( $50 \mathrm{~mm}$ TRIS, $\mathrm{pH} 8.0$ ) and incubation with lambda phosphatase (New England Biolabs) for $1 \mathrm{~h}$ at $30^{\circ} \mathrm{C}$.

Immunoblotting. Lysates were boiled $5 \mathrm{~min}$, then subjected to SDS/ PAGE (4-12\% gradient Bis-Tris, Invitrogen) and transferred to PVDF membrane (Invitrogen). Membranes were blocked $1 \mathrm{~h}$ in 5\% nonfat dry milk at room temperature and then incubated overnight in primary antibody at $4^{\circ} \mathrm{C}$. Membranes were washed $4 \times$ in PBS, incubated in HRPconjugated secondary antibody (1:5000) $1 \mathrm{~h}$, and then washed $4 \times$ in PBST (PBS $+0.1 \%$ Tween20). Proteins were detected with Immobilon Western Chemiluminescent HRP Substrate (Millipore) and visualized on Biomax MR film (Kodak). Primary antibodies were as follows: $\alpha$-ataxin-2 mouse antibody (BD), 1:500; $\alpha$-actin mouse monoclonal antibody, clone C4 (Millipore), 1:5000; $\alpha$-TDP-43 rabbit polyclonal antibody (Proteintech), 1:1000; $\alpha$-phosphorylated TDP-43 (409/410-1) mouse monoclonal antibody (Cosmo Bio), 1:1000; $\alpha$-cleaved caspase 3 rabbit antibody (Cell Signaling Technology), 1:500; $\alpha$-cleaved caspase 7 rabbit antibody (Cell Signaling Technology), 1:500; $\alpha$-cleaved caspase 8 rabbit antibody (Cell Signaling Technology), 1:500; $\alpha$-cleaved caspase 9 rabbit antibody (Cell Signaling Technology), 1:500; $\alpha$-cleaved PARP rabbit antibody (Cell Signaling Technology), 1:500. Immunoblots were quantified by densitometry using ImageJ software.

Immunohistochemistry. Patient brain tissue was deparaffinized before pretreatment using heat antigen retrieval with Bull's Eye Decloaker (BioCare Medical). Endogenous peroxidase was then blocked with 3\% hydrogen peroxide in PBS for 10 min. After washing with $0.1 \%$ PBST, sections were blocked with $10 \%$ goat serum in $0.5 \%$ PBST for $30-60 \mathrm{~min}$ at $25^{\circ} \mathrm{C}$. Sections were incubated with $\alpha$-TDP- 43 rabbit polyclonal antibody (Proteintech Group), 1:500, $\alpha$-cleaved caspase 3 rabbit antibody (Biocare), 1:100; $\alpha$-phosphorylated TDP-43 (409/410-1) mouse monoclonal antibody (Cosmo Bio), 1:100 in 0.1\% PBST overnight at $4^{\circ} \mathrm{C}$. After washing with $0.1 \%$ PBST, sections were incubated with biotinylated goat anti-mouse or rabbit IgG (1:200; Vector Laboratories) for $1 \mathrm{~h}$ at $25^{\circ} \mathrm{C}$. After washing with $0.1 \%$ PBST, sections were then incubated with Vectastain $\mathrm{ABC}$ (Vector Laboratories) for $45 \mathrm{~min}$. After washing with $0.1 \%$ PBST followed by $0.1 \mathrm{M}$ Tris, $\mathrm{pH} 7.5$, and $0.3 \mathrm{M} \mathrm{NaCl}$. Peroxidase activity was then detected with DAB (Sigma). For fluorescence immunohistochemistry, sections were incubated with ImmPRESS Anti-Rabbit or Anti-Mouse Ig (peroxidase) Polymer reagent (Vector Lab) followed by Tyramide Signal Amplification with FITC (PerkinElmer) or Texas-Red (NEN). Detailed immunohistochemistry protocols are available at http://www.med.upenn.edu/mcrc/histology_core/. Sections were imaged on a Nikon Eclipse 80i microscope using a Nikon DS-Ril camera and analyzed using Nikon NIS elements imaging software.

Caspase 3 activation and localization in ALS patient spinal cords was quantified using sections stained with immunofluorescence by counting the number of motor neurons with cleaved caspase 3 staining, nuclear cleaved caspase 3 staining, or cleaved caspase 3 staining in $>3$ cytoplasmic foci. The cleaved caspase 3 motor neurons counts were then calculated as a percentage of the total number of motor neurons counted in each section. Cleaved caspase 3 quantification was performed using sections stained using immunofluorescence. The quantification and staining patterns observed were verified using sections stained using chromogenic immunohistochemistry.

Statistical analyses. All statistical comparisons represent $p$ values calculated using one-way ANOVA followed by Tukey HSD post hoc test. All statistical calculations were performed using $R$ software. Differences were considered statistically significant with $p<0.05$.

\section{Results}

Intermediate-length ataxin 2 polyQ expansions enhance stress-induced accumulation of a phosphorylated TDP-43

\section{C-terminal fragment}

We previously demonstrated that intermediate-length polyQ expansions in ataxin 2 enhance its interaction with TDP-43 and promote the sequestration of TDP-43 from the nucleus to cytoplasmic stress granules (Elden et al., 2010). Phosphorylation, dephosphorylation, ubiquitination, and reversible aggregation play important roles in regulating stress granule formation and dynamics (Buchan and Parker, 2009; Thomas et al., 2011), and ubiquitin-modifying enzymes, kinases, phosphatases, and proteases are all present in stress granules (Kwon et al., 2007; White et al., 2007; Ohn et al., 2008; Tsai et al., 2008; Khong and Jan, 2011). Therefore, we hypothesized that the enhanced localization of TDP-43 to cytoplasmic stress granules conferred by ataxin 2 intermediate-length polyQ expansions (Elden et al., 2010) might make it more prone to pathological modifications. To investigate this, we first tested the effects of ataxin 2 polyQ expansions on 


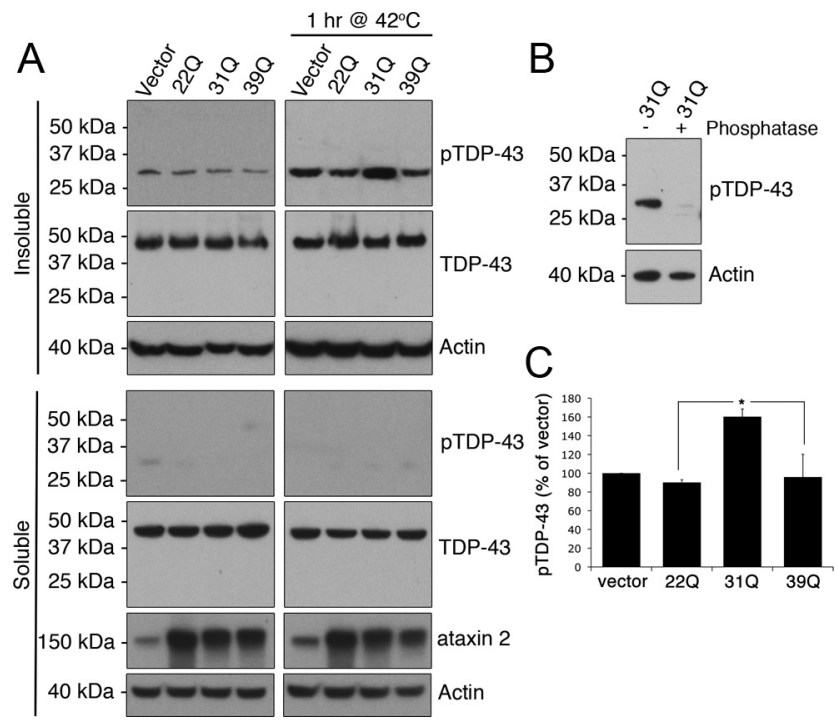

Figure 1. Intermediate-length ataxin 2 poly 0 expansions cause accumulation of a phosphorylated TDP-43 C-terminal fragment in HEK293 cells. A, HEK293 cells transfected with empty vector or ataxin 2 with increasing polyQ length $(220,310$, or 390) were heat shocked for $1 \mathrm{~h}$ at $42^{\circ} \mathrm{C}$, or control for $1 \mathrm{~h}$ at $37^{\circ} \mathrm{C}$, then lysed into soluble and insoluble fractions. An accumulation of insoluble pTDP-43 C-terminal fragment was seen with ataxin 2310 compared with empty vector or ataxin 2220 and 390 . B, Dephosphorylation of the insoluble fraction with dialysis and lambda phosphatase treatment removes the pTDP-43 band. C, Quantification from three independent experiments (pTDP-43 levels normalized to actin and compared with empty vector control; error bars represent SD; $\left.{ }^{*} p<0.001\right)$.

TDP-43 in transfected human HEK293T cells. We transfected cells with ataxin 2 constructs of increasing polyQ length (22Q (normal), 31Q (intermediate-length, associated with ALS risk), 39Q (SCA2 range), or an empty vector. We used a $1 \mathrm{~h}$ heat shock at $42^{\circ} \mathrm{C}$ as a stressor to induce the redistribution of endogenous TDP-43 from the nucleus to the cytoplasm (Freibaum et al., 2010; Liu-Yesucevitz et al., 2010; McDonald et al., 2011) followed by immunoblotting of soluble and insoluble protein fractions with a phospho-specific TDP-43 antibody (409/410) to assess the level of TDP-43 phosphorylation. We did not detect phosphorylated TDP-43 (pTDP-43) in the soluble fraction of control or heatshocked cells (Fig. 1A), consistent with phosphorylation associating with insoluble TDP-43 (Neumann et al., 2006; Igaz et al., 2009). However, in the insoluble fraction of heat-shocked cells we found a significant increase in an $\sim 30 \mathrm{kDa}$ pDP-43 fragment in cells transfected with $31 \mathrm{Q}$ ataxin 2, but not in cells transfected with empty vector, 22Q or 39Q (Fig. 1 A,C). Dephosphorylation of cell extracts with a phosphatase eliminated the pTDP-43 band (Fig. $1 \mathrm{~B}$ ), confirming that this fragment represented a phosphorylated form of TDP-43. None of the ataxin 2 constructs caused an increase in pTDP-43 in nonheat-shocked cells (Fig. 1A), suggesting that ataxin 2 polyQ expansions do not directly enhance TDP-43 phosphorylation under normal conditions, but rather lower the threshold for TDP-43 modifications under situations of stress.

We next sought to validate these findings using cell lines from ALS patients expressing endogenous levels of both ataxin 2 and TDP-43. We obtained patient-derived lymphoblast cells from ALS cases harboring intermediate-length polyQ expansions (4 cases; 27Q, 29Q, 31Q, 32Q), ALS cases with normal-range ataxin 2 repeat lengths (3 cases; all 22Q), and from one individual with SCA2 (40Q). Utilizing the same heat shock paradigm $\left(42^{\circ} \mathrm{C}\right.$ for $1 \mathrm{~h}$ ), we found that cell lines with intermediate-length ataxin 2 polyQ expansions exhibited a significant accumulation of the insoluble pTDP-43 C-terminal fragment compared with normallength or SCA2-expanded cell lines (Fig. 2A). Densitometry of immunoblots from multiple independent experiments showed a significant accumulation of this fragment in cell lines with 3132Q $(p<0.01)$, but not in the SCA2 patient cell line with $40 \mathrm{Q}$ (Fig. 2 B). Interestingly, the cell lines with 27-29Q showed a slight increase in the pTDP-43 fragment, but it did not reach statistical significance (Fig. $2 \mathrm{~B}$ ). Remarkably, in both cell models (transfected HEK293T cells and ALS patient-derived lymphoblast cells), the accumulation of the pTDP-43 fragment was specific to ALS-associated intermediate-length polyQ expansions and was not seen in cells expressing normal-length or SCA2-length expansions. We did not observe full-length pTDP-43 in either of the cell models in any fractions, suggesting that, at least under these conditions, phosphorylation may be occurring subsequent to the generation of the $\sim 30 \mathrm{kDa}$ fragment. Phosphorylation and truncation are hallmark features of TDP-43 pathology in disease (Neumann et al., 2006). Our findings provide a role for ataxin 2 intermediate-length polyQ expansions in enhancing these key pathological modifications under situations of stress.

\section{Intermediate-length ataxin 2 polyQ expansions enhance caspase activation in response to cellular stress}

We next sought to define the origin of the $\sim 30 \mathrm{kDa}$ pTDP-43 fragment. PolyQ tract expansions in other proteins have been shown to cause caspase activation and lead to apoptosis (Evert et al., 2000; Ross, 2002); there is evidence that ataxin 2 may promote apoptosis when overexpressed in cell models (Huynh et al., 2003; Wiedemeyer et al., 2003), and caspases have been shown to directly cleave TDP-43 (Zhang et al., 2007; Dormann et al., 2009). Therefore, we hypothesized that intermediate-length ataxin 2 polyQ expansions might enhance caspase activation upon cellular stress, leading to an increase in TDP-43 cleavage and further pathological modifications such as phosphorylation. Using the human patient-derived lymphoblast cells with ataxin 2 polyQ lengths of either 22Q or 29Q and the same heat shock paradigm, we screened by immunoblot for caspase activation. As a positive control, we treated a 22Q cell line with staurosporine to induce caspase activation broadly (Dormann et al., 2009). Remarkably, we found that caspase 3 and 7 were strongly activated by heat shock in the 29Q ataxin 2 expanded cell line but not in the 22Q ataxin 2 cell line (Fig. 3). Caspase 8 was not activated in the 29Q cell line but was present in staurosporine-treated cells, and caspase 9 was only weakly activated (Fig. 3). Interestingly, in both the staurosporine-treated cells and the 29Q cell line, ataxin 2 itself was also cleaved. It has previously been reported that ataxin 2 harbors a caspase cleavage site, and the fragment we detect by immunoblot corresponds to the predicted C-terminal cleavage product size (Huynh et al., 2000). Notably, caspase cleavage of ataxin 3 and ataxin 7 contribute to pathogenicity in models of SCA3 and SCA7, respectively (Young et al., 2007; Jung et al., 2009); thus, it is possible that a similar cleavage mechanism contributes to ataxin 2 pathogenesis. Together, these data suggest that intermediate-length ataxin 2 polyQ expansions might poise cells to respond to stress by lowering the threshold for activating cellular caspases.

The potent ability of caspase 3 to cleave TDP-43 in vitro (Zhang et al., 2007; Dormann et al., 2009; Nishimoto et al., 2010) led us to focus on the activation of caspase 3 by ataxin 2 intermediate-length polyQ expansions. In both the HEK293T cell model and the patient-derived lymphoblast cell model we found that in all cases ataxin 2 intermediate-length polyQ expansions (27-32Q), but not normal (22Q) or SCA2-length (>34Q), 
caused a robust increase in caspase 3 activation upon cellular stress (Fig. 4A,B). Densitometry of immunoblots from multiple independent experiments using the patient-derived lymphoblast cell lines showed a significant increase in the amount of activated caspase 3 in cell lines with 31-32Q $(p=0.001)$ and an increase in cell lines with 27-29Q, although this did not reach statistical significance $(p=$ $0.057)$. It has previously been reported that WT ataxin 2, but not SCA2 polyQexpanded ataxin 2, promotes apoptosis via caspase activation (Wiedemeyer et al., 2003). Our results are consistent with these findings and suggest that intermediate-length ataxin 2 polyQ expansions enhance the effect on caspase 3 activation, whereas longer polyQ expansions (i.e., SCA2 range) have an inhibitory effect. These data provide a potential mechanistic explanation for how different polyQ lengths in ataxin 2 can be associated with different diseases (ALS vs SCA2).

\section{Caspase 3 inhibitors reduce TDP-43 pathological modifications}

Our data so far are consistent with a model whereby ataxin 2 intermediate-length polyQ expansions poise a cell to respond to stress by activating caspases, which in turn cleave TDP-43, leading to its phosphorylation. However, it is possible that caspase activation is downstream or parallel to TDP-43 cleavage and phosphorylation. To distinguish between these possibilities, we used caspase inhibitors in the same heat shock cell models. Using transfected HEK293T cells, 31Q ataxin 2 resulted in accumulation of an insoluble pTDP-43 fragment upon heat shock compared with 22Q ataxin 2 (Fig. 5A). A $24 \mathrm{~h}$ incubation with Z-DEVD-FMK, a caspase 3 specific inhibitor, reduced the accumulation of pTDP-43 after heat shock (Fig. $5 B, p<0.05$ ). We also tested two ALS patient-derived lymphoblast cell lines (29Q and $32 \mathrm{Q}$ ), and observed that the accumulation of the insoluble pTDP-43 fragment following heat shock in both of these cell lines was also significantly reduced by treatment with the caspase 3 inhibitor (Fig. $5 C, D, p<0.05$ ). These results provide evidence that caspase 3 activation upon heat shock is upstream of TDP-43 cleavage and phosphorylation, but leave open the question of whether caspase 3 directly cleaves TDP-43 or is upstream of cleavage.

\section{Intermediate-length ataxin 2 polyQ expansions increase TDP-43 pathological modifications and enhance stress-induced caspase 3 activation in differentiated BE(2)M17 neuroblastoma cells}

To determine the relevance of our findings in nondividing neuronlike cells, we examined the effect of ataxin 2 intermediate-length polyQ expansions in differentiated BE(2)-M17 neuroblastoma cells (M17 cells). We transfected M17 cells with ataxin 2 constructs of increasing polyQ length (22Q (normal), 31Q (intermediate-length, associated with ALS risk), 39Q (SCA2 range) or an empty vector. Forty-eight hours after transfection, cells were differentiated using low serum and retinoic acid for $5 \mathrm{~d}$. Following differentiation, cells were treated with a $1 \mathrm{~h}$ heat shock at $42^{\circ} \mathrm{C}$ as a stressor or $37^{\circ} \mathrm{C}$ as a control. Differentiated M17 cells showed extension of multiple long neurites and reduced confluency compared with cells grown in nondifferentiation media. We found that differentiated M17 cells expressing ataxin 2 with $31 \mathrm{Q}$ exhibited a significant accumulation of the insoluble pTDP-43 C-terminal fragment $(p<0.05)$ (Fig. 6A,B) and a significant increase in activated caspase $3(p<0.05)$ (Fig. $6 C, D)$ compared with cells expressing ataxin 2 with $22 \mathrm{Q}$ or $39 \mathrm{Q}$. Interestingly, there was some insoluble pTDP-43 fragment present even in the nonheat-shocked cells, perhaps because of a longer time in culture or increased sensitivity of differentiated cells to ataxin 2 overexpression. Together, these results validate our findings from HEK293T and patient-derived lymphoblast cells to nondividing neuron-like cells.

\section{Caspase 3 activation in motor neurons of ALS patients with ataxin 2 intermediate-length polyQ expansions}

To further examine the relevance of our observations in cell lines to human ALS patients, we examined activated caspase 3 by immunohistochemistry in postmortem spinal cord tissue from ALS patients with either normal-length ataxin $2(n=4$; all 22Q) or intermediatelength polyQ-expanded ataxin $2(27 \mathrm{Q}, n=2 ; 32 \mathrm{Q}, n=2)$. The patients were similar in age of onset [normal-length ataxin 2 polyQ group mean $=53(\mathrm{SD}=13.7)$, intermediate-length ataxin 2 polyQ group mean $=59(\mathrm{SD}=11.3)]$. The ALS patients with ataxin 2 polyQ expansions showed a striking increase in the percentage of motor neurons with activated caspase 3 staining compared with ALS patients with normal-length ataxin 2 (Fig. 7A,B). Furthermore, the activated caspase 3 staining in ataxin 2 polyQexpanded ALS cases was consistently localized within cytoplasmic foci, rarely seen in motor neurons from ALS patients with normallength ataxin 2 (Fig. $7 A, C$ ). There was no difference in the nuclear staining of cleaved caspase 3 between the two groups. Thus, consistent with our results from the cellular models, ataxin 2 intermediatelength polyQ expansions are associated with increased caspase 3 activation in the degenerating motor neurons of ALS patients. These 


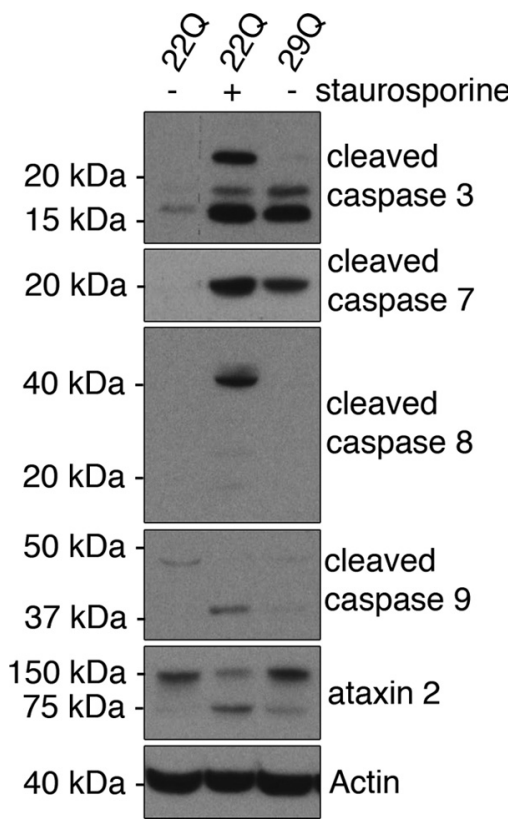

Figure 3. Intermediate-length ataxin 2 polyQ expansions enhance caspase activation in response to cellular stress. Patient-derived lymphoblast cell lines with either ataxin 2220 or 290 were heat shocked for $1 \mathrm{~h}$ at $42^{\circ} \mathrm{C}$, or a cell line with ataxin $222 \mathrm{Q}$ was treated for $3 \mathrm{~h}$ with $1 \mu \mathrm{m}$ staurosporine at $37^{\circ} \mathrm{C}$. Cells were lysed into soluble and insoluble fractions. Lysates were immunoblotted with a panel of caspase antibodies to determine which caspases were activated. Caspase 3 and caspase 7 showed strong activation/cleavage in the ataxin 2290 cell line but not in the ataxin 2220 cell line. Caspase 8 did not show activation except in the staurosporine-treated cell line, and caspase 9 was only weakly activated in the 290 cell line. Ataxin 2 appeared to be cleaved in the heat shocked 290 cell line and in the staurosporine-treated 220 cell line.
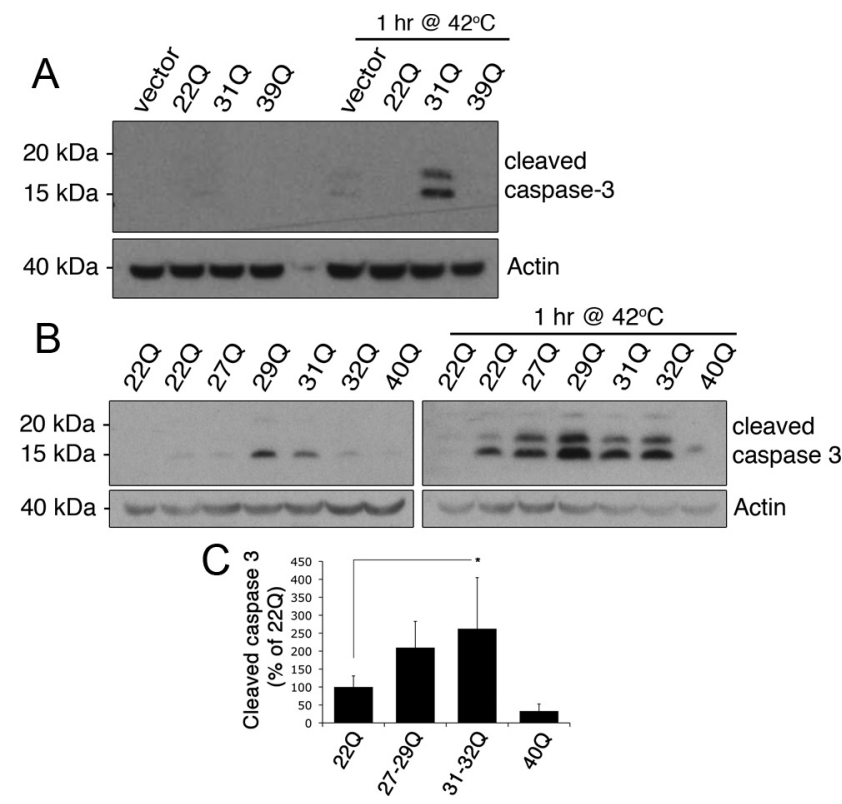

Figure 4. Ataxin 2 intermediate-length polyQ expansions result in caspase 3 activation following heat-shock. $A$, HEK293T cells transfected with empty vector or ataxin 2 with increasing poly $\mathrm{Q}$ length $(22 \mathrm{Q}, 31 \mathrm{Q}$, or $39 \mathrm{Q})$ were heat shocked for $1 \mathrm{~h}$ at $42^{\circ} \mathrm{C}$, then analyzed for caspase 3 activity by immunoblot for cleaved caspase $3 . \boldsymbol{B}$, ALS patient-derived lymphoblast cell lines with normal or polyQ-expanded ataxin 2 were heat shocked for $1 \mathrm{~h}$ at $42^{\circ} \mathrm{C}$, then analyzed for caspase 3 activation by immunoblot. C, Quantification of three independent experiments (cleaved caspase 3 levels normalized to actin and compared with levels in 220 control cell lines; error bars represent $S D ;{ }^{*} p<0.01$ ).
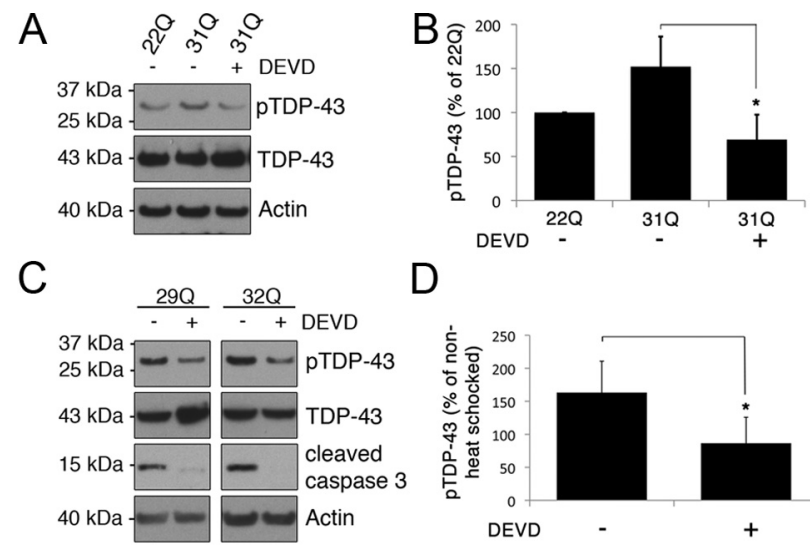

$D$

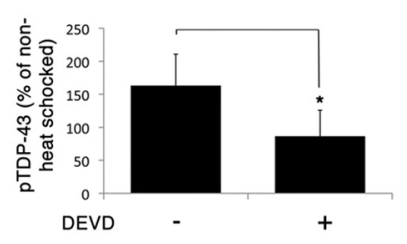

Figure 5. Caspase 3 inhibition reduces accumulation of the pTDP-43 C-terminal fragment. $A$ HEK293T cells transfected with ataxin 2 of 220 or 310 were treated with vehicle alone or Z-DEVD-FMK for $24 \mathrm{~h}$, heat shocked at $42^{\circ} \mathrm{C}$ for $1 \mathrm{~h}$, and then lysed into soluble and insoluble fractions. Cells with ataxin 2310 showed an accumulation of pTDP-43 fragment compared with $22 Q$, but this accumulation is dissipated by inhibition of caspase 3 . B, Quantification of three separate experiments ( $p$ TDP-43 levels normalized to actin and compared with pTDP-43 levels in 220 contro cell lines; error bars represent SD; $\left.{ }^{*} p<0.05\right)$. C, ALS patient-derived lymphoblast cell lines with intermediate-length polyQ-expanded ataxin 2 were treated with vehicle alone or Z-DEVD-FMK for $24 \mathrm{~h}$, then heat shocked at $42^{\circ} \mathrm{C}$ for $1 \mathrm{~h}$ (or control for $1 \mathrm{~h}$ at $37^{\circ} \mathrm{C}$ ) and lysed into soluble and insoluble fractions. Accumulation of the PTDP-43 fragment seen with heat shock in ataxin 2 polyQ-expanded cells was reduced by caspase 3 inhibition. $D$, Quantification of two separate experiments from two separate cell lines (PTDP-43 levels normalized to actin and compared with pTDP-43 levels in nonheatshocked cells; error bars represent SD; $\left.{ }^{*} p<0.05\right)$.

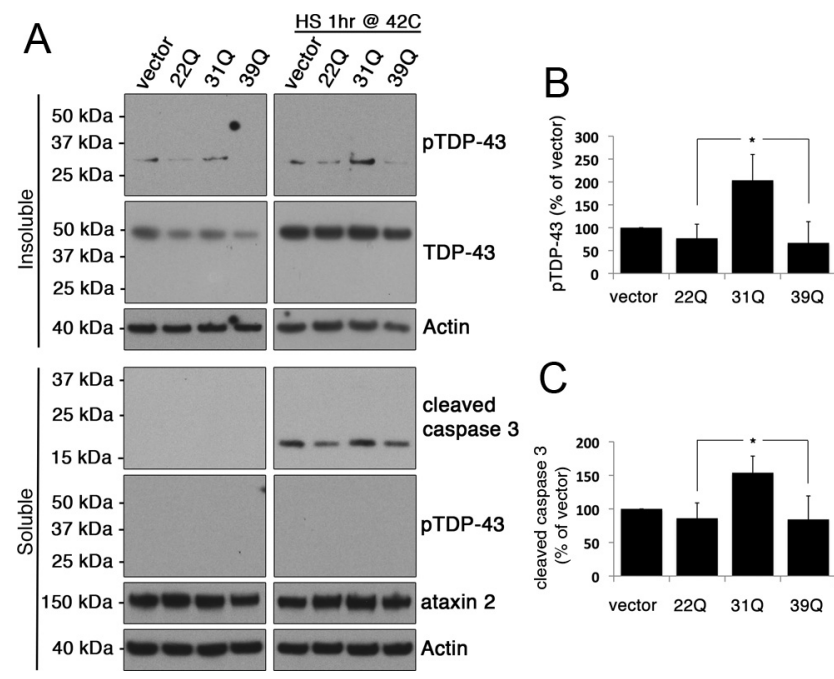

Figure 6. Accumulation of pTDP- 43 and increased caspase 3 activation in differentiated BE(2)M17 cells expressing ataxin 2 with intermediate-length polyQ expansion. BE(2)-M17 neuroblastoma cells transfected with empty vector or ataxin 2 with increasing polyQ length (22Q, 310 , or 390) were differentiated for $5 \mathrm{~d}$ and heat shocked for $1 \mathrm{~h}$ at $42^{\circ} \mathrm{C}$, or control for $1 \mathrm{~h}$ at $37^{\circ} \mathrm{C}$, then lysed into soluble and insoluble fractions. $A$, An accumulation of insoluble pTDP-43 C-terminal fragment was seen with ataxin 2310 compared with empty vector or ataxin 2220 and 390 . There was also an increase in cleaved caspase 3 in cells expressing 310 , but not 220 or 390. $\boldsymbol{B}$, Quantification from three independent experiments (pTDP-43 levels normalized to actin and compared with empty vector control; error bars represent SD; $\left.{ }^{*} p<0.05\right)$. C, Quantification from three independent experiments (cleaved caspase 3 levels normalized to actin and compared with empty vector control; error bars represent SD; ${ }^{*} p<0.05$ ).

data indicate that cytoplasmic caspase 3 activation in motor neurons defines a new pathological feature of ALS associated with ataxin 2 intermediate-length polyQ expansions.

To examine the impact of the cytoplasmic localization of cleaved caspase 3 on TDP-43 inclusion formation, we costained 
spinal cord sections from ALS patients harboring ataxin 2 polyQ expansions with pTDP-43 and cleaved caspase 3 antibodies (Fig. 8). Motor neurons from ALS patients harboring ataxin 2 with $22 \mathrm{Q}$ showed some nuclear and rarely cytoplasmic cleaved caspase 3 staining (Fig. $8 A$ ). In these cases, cleaved caspase 3 staining did not correlate with the presence of pTDP-43 pathology. Analysis of motor neurons from ALS patients with polyQexpanded ataxin 2 showed that motor neurons with cytoplasmic foci of cleaved caspase 3 completely lacked or contained only very small pTDP-43 preinclusions (Fig. $8 \mathrm{~B}$ ). Interestingly, in motor neurons containing cleaved caspase 3 cytoplasmic foci, it appeared that caspase 3 was excluded from the nucleus (Figs. $7 A ; 8 B, C$ ). Motor neurons containing larger pTDP-43 preinclusions showed less distinct, fewer, or no cytoplasmic cleaved caspase 3 foci (Fig. 8C,D). Notably, motor neurons containing large skein-like inclusions very rarely, if ever, contained cleaved caspase 3 foci (Fig. $8 E$ ), which indicates that the accumulation of cleaved caspase 3 cytoplasmic foci is likely present early in pTDP-43 inclusion formation. Together with the cellular data, this suggests that cleaved caspase 3 activation plays a role early in the pathological cascade.

\section{Discussion}

Ataxin 2 intermediate-length polyQ expansions are a genetic risk factor for ALS (Elden et al., 2010; Lagier-Tourenne and Cleveland, 2010; Chen et al., 2011; Daoud et al., 2011; Fischbeck and Pulst, 2011; Lee et al., 2011; Ross et al., 2011; Sorarù et al., 2011; Van Damme et al., 2011; Gispert et al., 2012; Van Langenhove et al., 2012). Here, we have investigated the mechanism by which these polyQ expansions might confer risk for the disease. Using three independent model systems (transfected human HEK293T cells, ALS patient-derived lymphoblast cell lines, and differentiated human M17 neuroblastoma cells), we found that ataxin 2 intermediate-length polyQ expansions enhance the production of a phosphorylated TDP-43 C-terminal fragment upon cellular stress. Remarkably, this effect is specific to intermediate-length polyQ expansions and is not caused by normal-length (22Q) or even SCA2length $(>34 \mathrm{Q})$ polyQ-expanded ataxin 2. Phosphorylation and truncation of TDP-43 are hallmark features of pathology in ALS and have been used to illuminate pathological forms of TDP-43 (Arai et al., 2006; Neumann et al., 2006; Hasegawa et al., 2008; Inukai et al., 2008; Neumann et al., 2009), as well as to model features of TDP-43 proteinopathy in various cell and animal models (Igaz et al., 2009; Nonaka et al., 2009; Liachko et al., 2010). Our results provide evidence that ataxin 2 intermediate-length polyQ expansions play a fundamental role in enhancing these modifications to TDP-43.

We also found that ALS-associated ataxin 2 polyQ expansions, but not normal or SCA2-length expansions, enhance caspase ac-
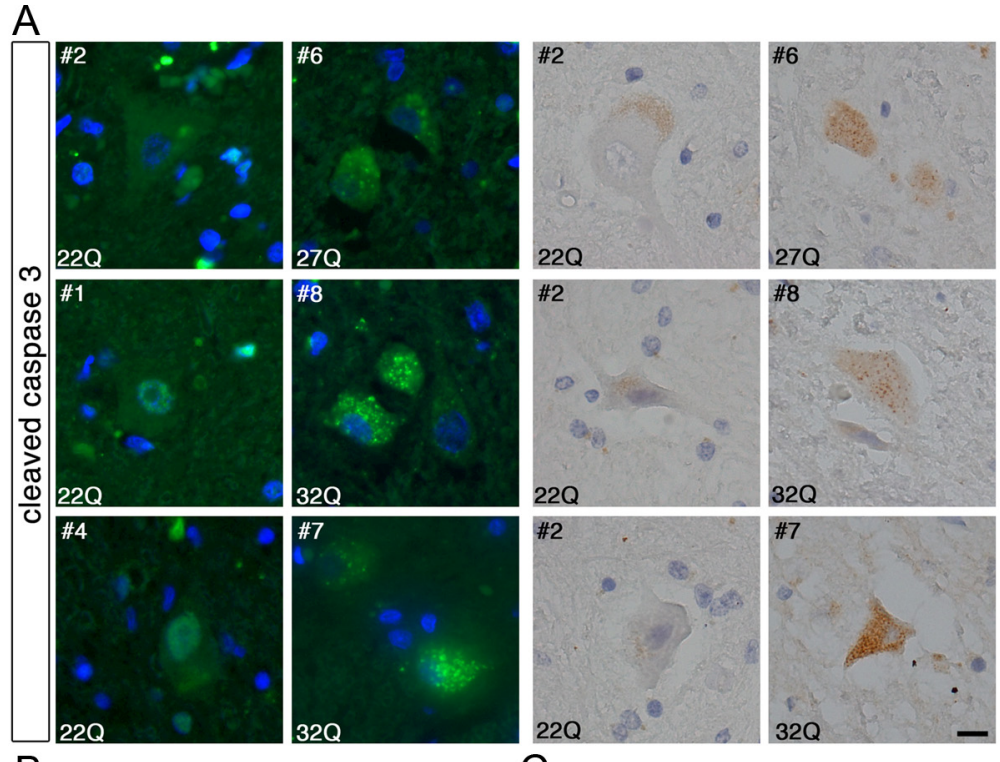

$\mathrm{C}$

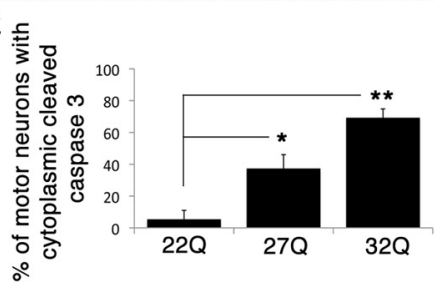

D
\begin{tabular}{|c|c|c|c|c|c|c|c|c|}
\hline $\begin{array}{c}\text { Case } \\
\#\end{array}$ & $\begin{array}{c}\text { ALS patient } \\
\text { ataxin 2 } \\
\text { polyQ } \\
\text { length }\end{array}$ & $\begin{array}{c}\text { Total Motor } \\
\text { Neurons } \\
\text { Counted }\end{array}$ & $\begin{array}{c}\text { cleaved } \\
\text { caspase } \mathbf{3}\end{array}$ & $\begin{array}{c}\text { Cytoplasmic } \\
\text { cleaved } \\
\text { caspase } \mathbf{3}\end{array}$ & $\begin{array}{c}\text { Nuclear } \\
\text { cleaved } \\
\text { caspase } \mathbf{3}\end{array}$ & $\%$ \\
\hline $\mathbf{1}$ & $\mathbf{2 2 Q}$ & 91 & 32 & 35 & 12 & 13 & 20 & 22 \\
\hline $\mathbf{2}$ & $\mathbf{2 2 Q}$ & 81 & 35 & 43 & 4 & 5 & 31 & 38 \\
$\mathbf{3}$ & $\mathbf{2 2 Q}$ & 29 & 10 & 34 & 1 & 3 & 9 & 31 \\
\hline $\mathbf{4}$ & $\mathbf{2 2 Q}$ & 41 & 11 & 27 & 0 & 0 & 11 & 27 \\
\hline $\mathbf{5}$ & $\mathbf{2 7 Q}$ & 45 & 30 & 67 & 14 & 31 & 16 & 36 \\
$\mathbf{6}$ & $\mathbf{2 7 Q}$ & 69 & 45 & 65 & 30 & 43 & 15 & 22 \\
\hline $\mathbf{7}$ & $\mathbf{3 2 Q}$ & 26 & 19 & 73 & 17 & 65 & 2 & 8 \\
\hline $\mathbf{8}$ & $\mathbf{3 2 Q}$ & 97 & 83 & 86 & 71 & 73 & 12 & 12 \\
\hline
\end{tabular}

Figure 7. Caspase 3 activation in motor neurons of ALS patients with ataxin 2 intermediate-length polyQ expansions. Spinal cord sections of ALS patients with 220 ataxin 2 or 27-31Q ataxin 2 were stained with cleaved caspase 3 antibody, and motor neurons were analyzed for staining and localization. Case numbers and ataxin 2 polyQ lengths are indicated. $\boldsymbol{A}$, Immunofluorescence or light micrographs of cleaved caspase 3 staining in motor neurons (scale bar, $10 \mu \mathrm{m}$ ). $\boldsymbol{B}$, Quantification of the percentage neurons counted with $>3$ cytoplasmic foci of cleaved caspase 3 (error bars represent SD, ${ }^{*} p<0.01,{ }^{* *} p<0.001$ ). D, Table showing motor neuron counts from different patients.

tivation in response to cellular stress, including a significant activation of caspase 3. These results suggest that intermediatelength ataxin 2 polyQ expansions could poise cells to become hyper-responsive to stress. It has previously been reported that overexpressed wild-type, but not SCA2-expanded (79Q) ataxin 2 causes increased caspase activity and apoptosis (Wiedemeyer et al., 2003). However, other studies have found that polyQexpanded ataxin 2 (58Q) can cause an increase in cell death and caspase activation compared with nonexpanded ataxin 2 . These discrepancies could be due to different cell types, different methods to measure cell death, and/or different experimental conditions (Huynh et al., 2003; Ng et al., 2007). Perhaps ALSassociated ataxin 2 intermediate-length polyQ expansions enhance a "normal" function of the protein, whereas SCA2-length polyQ expansions confer a different novel or toxic function. Given its important role in stress granule assembly and function 

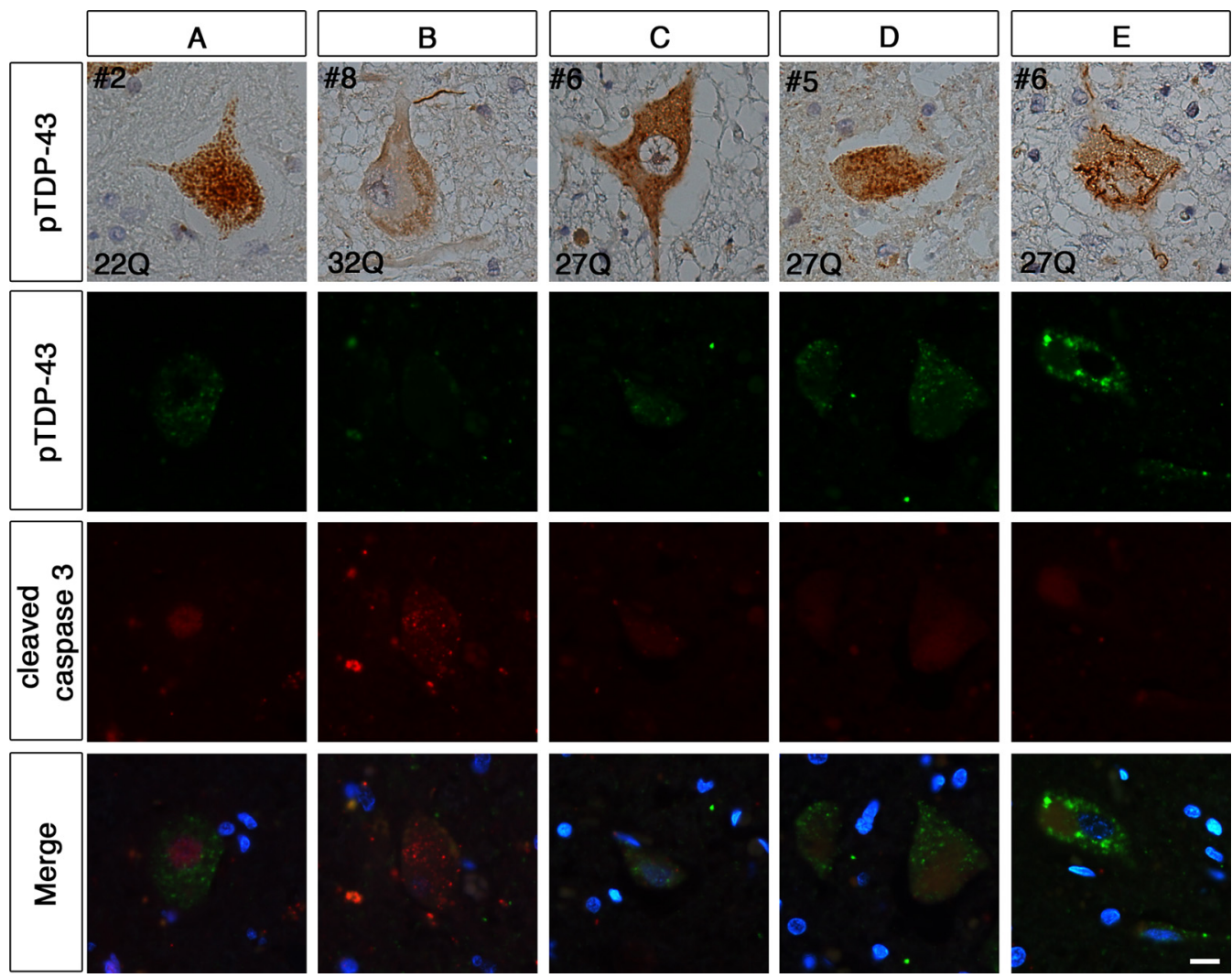

Figure 8. Phosphorylated TDP-43 and cleaved caspase 3 staining in motor neurons of ALS patients. Spinal cord sections of ALS patients with 220 ataxin $2(\boldsymbol{A})$ or $27-310$ ataxin $2(\boldsymbol{B}-\boldsymbol{E})$ were costained with pTDP-43 and cleaved caspase 3 antibodies. Case numbers and ataxin 2 polyQ lengths are indicated. Immunofluorescence or light micrographs show pTDP-43 and cleaved caspase 3 staining in motor neurons. $\boldsymbol{A}, 22 \mathrm{Q}$ ataxin 2 cases showed occasional nuclear cleaved caspase 3 staining with no correlation to the presence of pTDP-43 inclusions. $\boldsymbol{B}-\boldsymbol{E}$, Ataxin 2 polyQ-expanded motor neurons with cytoplasmic foci of cleaved caspase 3 showed little or no pTDP-43 preinclusions ( $\boldsymbol{B})$, Motor neurons with pTDP-43 preinclusions had fewer cleaved caspase 3 cytoplasmic foci $(\boldsymbol{C}, \boldsymbol{D})$, and motor neurons with pTDP-43 inclusions had rare or no cleaved caspase 3 foci (E). Top panels are light micrographs of pTDP-43 staining from ALS patients demonstrating similar TDP-43 pathology by chromogenic staining (scale bar, $10 \mu \mathrm{m}$ ).

(Nonhoff et al., 2007; Swisher and Parker, 2010), ataxin 2 could serve as a linchpin linking signaling between cellular stress responses and apoptotic cascades via its interactions within stress granules. Indeed, stress granules and components within these structures are crucial in the life-or-death cellular decision whether or not to enter apoptosis in response to prolonged stress (Buchan and Parker, 2009). Mutations that enhance this function of ataxin 2 (i.e., intermediate-length polyQ expansions) may cause a more robust cellular response upon stress.

Multiple recent studies have confirmed an association of intermediate-length ataxin 2 polyQ expansions with risk for ALS. However, the exact ataxin 2 polyQ expansion threshold for ALS risk (e.g., $27-33 \mathrm{Q},>29 \mathrm{Q}$, or $>30 \mathrm{Q}$, etc.), seems to vary slightly depending on the population assessed (Elden et al., 2010; Chen et al., 2011; Daoud et al., 2011; Fischbeck and Pulst, 2011; Lee et al., 2011; Ross et al., 2011; Sorarù et al., 2011; Van Damme et al., 2011; Gispert et al., 2012; Van Langenhove et al., 2012). This variation is further complicated by the finding that rare neurologically normal controls have been found to contain expansions 31Q (Elden et al., 2010, Ross et al., 2011, Daoud et al., 2011, Gispert et al., 2012). Additionally, although the ataxin 2 polyQ expansion threshold for SCA2 has been defined as $>34 \mathrm{Q}$, a number of studies have identified polyQ expansions larger than this in ALS patients (Daoud et al., 2011, Gispert et al., 2012). Finally, there are reports of ALS and SCA2 comorbidity in patients harboring large SCA2-associated ataxin 2 polyQ expansions (Infante et al., 2004; Nanetti et al., 2009). Together, these data suggest that a threshold for ataxin 2 polyQ length for ALS or SCA2 is very likely dependent on additional genetic and environmental factors, and for a set population the threshold is a spectrum of vulnerability, rather than a distinct cutoff. The mechanistic data we present here further support this notion: ataxin 2 with $27-29 \mathrm{Q}$ show an increase in heat shock induced caspase 3 activation, but this increase does not reach statistical significance until 31-32Q. However, in the analysis of ALS patient spinal cords, the differences in caspase activation and localization were seen in both sets of patients with $27 \mathrm{Q}$ and $32 \mathrm{Q}$, and these increases were polyQ expansion length dependent.

Previous studies indicate that TDP- 43 can be cleaved by caspase 3 and that this cleavage product is present in disease (Zhang et al., 2007; Dormann et al., 2009; Nishimoto et al., 2010). We find a robust ataxin 2 intermediate-length polyQ expansiondependent activation of caspase 3 upon cellular stress. This activation could play a role in cleavage of TDP-43, as inhibition of caspase 3 reduces the accumulation of the pTDP-43 cleavage fragment. We examined autopsy tissue from ALS patients with intermediate-length polyQ-expanded ataxin 2 and found an increase in activated caspase 3 compared with ALS patients with normal-length ataxin 2. These data support the idea that intermediate-length polyQ expansions in ataxin 2 are associated with increased caspase 3 activity in motor neurons and warrants further investigation into this mechanism. We also observed that activated caspase 3 in the ataxin 2 polyQ-expanded cases was localized within discrete cytoplasmic foci, which could be stress 


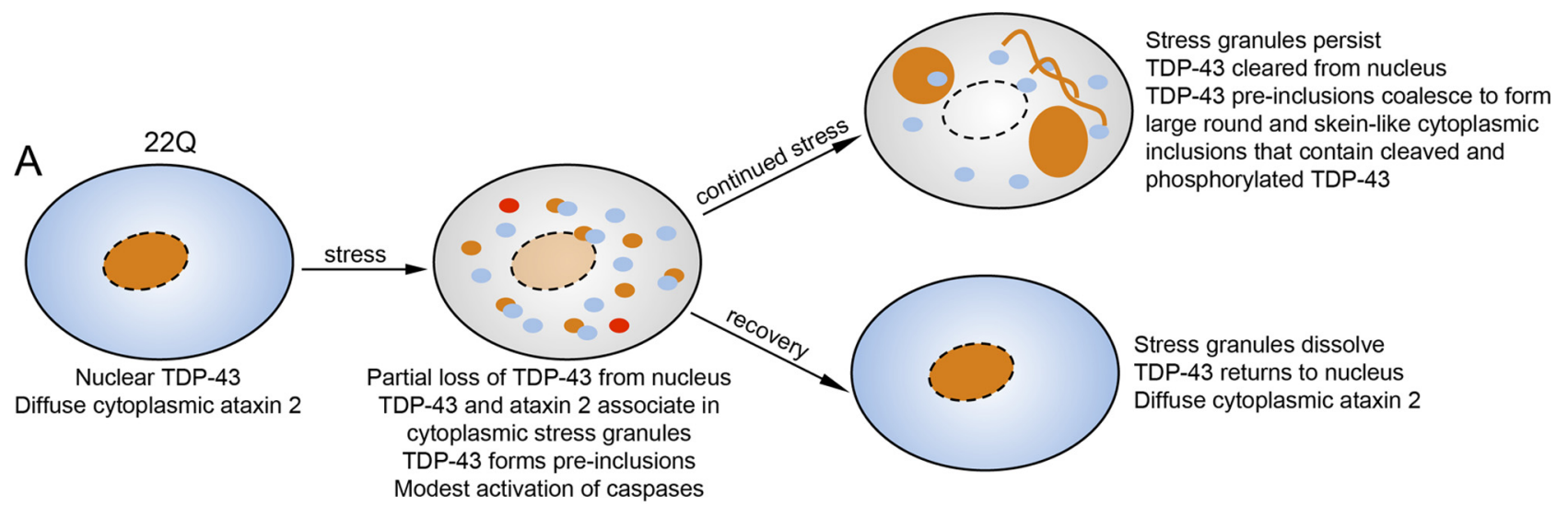

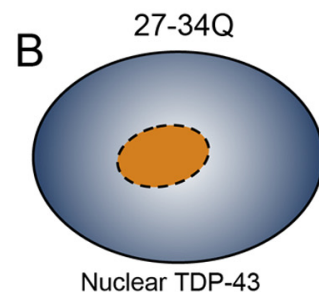

Diffuse cytoplasmic ataxin 2

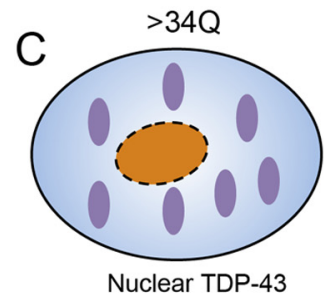

cytoplasmic ataxin 2 aggregates

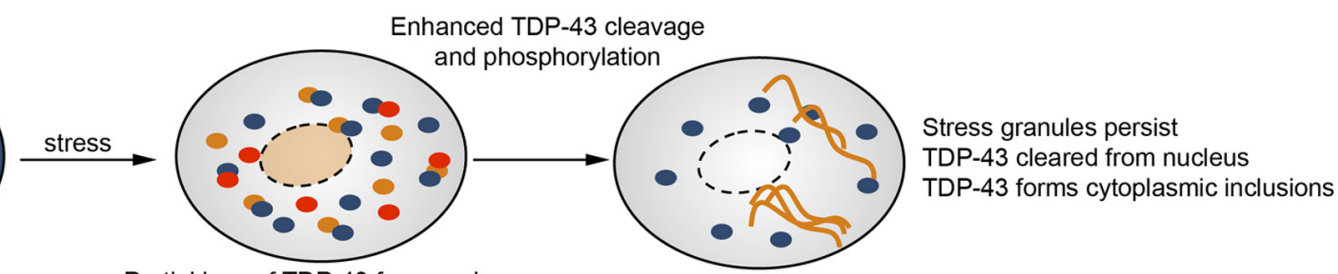

Partial loss of TDP-43 from nucleus TDP-43 and ataxin 2 associate in cytoplasmic stress granules TDP-43 forms pre-inclusions Strong activation of caspases
TDP -43

ataxin $2(22 Q)$

ataxin $2(27-34 Q)$

ataxin $2(>34 Q)$

activated caspase 3

Figure 9. A model to explain the effect of ataxin 2 intermediate-length polyQ expansions on TDP-43 in response to cellular stress. $\boldsymbol{A}$, In ALS patients with normal ataxin 2 polyQ length (22Q), TDP-43 is localized to the nucleus and ataxin 2 is diffuse in the cytoplasm. Upon cellular stress, ataxin 2 localizes to stress granules, TDP-43 partially leaves the nucleus and also associates with stress granules, accompanied by a slight activation of caspase 3. Following the stress, cells recover, stress granules dissolve, and TDP-43 returns to the nucleus. If the stress continues, stress granules persist, TDP-43 is cleared from the nucleus, cleaved and phosphorylated, and coalesces into large round or skein-like cytoplasmic aggregates. $\boldsymbol{B}$, In cells with ALS-associated ataxin 2 intermediate-length polyQ expansions (27-340), the threshold for activating caspases in response to stress is lowered. Therefore, caspase 3 is strongly activated upon cellular stress. Increased caspase activation leads to enhanced TDP-43 cleavage and phosphorylation, which drives cytoplasmic aggregation and nuclear clearance. Because the kinetics of TDP-43 cytoplasmic aggregation may be different in ALS cases with and without ataxin 2 polyQ expansions, the morphologies of the TDP-43 aggregates at end stage might be different (Hart et al., 2012 ). $C$, In spinocerebellar ataxia 2 (SCA2), in which patients harbor long ataxin 2 poly $Q$ expansions ( $>340$ ), ataxin 2 can aggregate in the cytoplasm and this could cause toxic gain-of-function effects, potentially unrelated to the normal function in cellular stress responses, which might lead to distinct cellular phenotypes and clinical presentation.

granules, or perhaps small inclusions. Analysis of cleaved caspase 3 and pTDP-43 costaining indicated that cytoplasmic foci containing cleaved caspase 3 are likely present early in pTDP-43 inclusion formation and thus are likely an early event in the pathological cascade. These findings define a new feature of ALS pathology specific to cases harboring ataxin 2 intermediatelength polyQ expansions.

Based on these findings, we propose a model whereby the presence of ataxin 2 intermediate-length polyQ expansions increases the likelihood for TDP-43 pathological modifications by lowering the threshold by which cells activate caspases upon cellular stress (Fig. 9). Stress-induced caspase activation could result in promiscuous TDP-43 cleavage, setting off a pathological cascade that leads to the accumulation of insoluble phosphorylated TDP-43 fragments and motor neuron death. There are certainly other routes to TDP-43 pathology in ALS independent of ataxin 2. For example, TDP-43 mutations, which are associated with rare familial and sporadic ALS cases, might cause disease by in- creasing the aggregation or stability of the protein (Johnson et al., 2009; Barmada et al., 2010; Ling et al., 2010), which could lead to cytoplasmic mislocalization. Indeed, we recently reported that ALS cases with ataxin 2 intermediate-length ataxin 2 polyQ expansions are characterized by distinct TDP-43 pathological features (Hart et al., 2012). Perhaps this distinct pathology is the result of a slightly different mechanism that results in TDP-43 pathology. Thus, all ALS mechanisms need not connect to ataxin 2 , and it is likely that there are multiple independent mechanisms (e.g., SOD1 mutation, FUS mutation, ataxin 2 polyQ expansions, etc.) that lead to motor neuron dysfunction and eventual degeneration.

The findings presented here have clear implications for ALS etiology and treatment, whereby a genetic risk factor alters the processing of the toxic disease protein TDP-43. If indeed caspase 3 is cleaving TDP-43 in ataxin 2 polyQ-expanded cases, this could represent a target for therapeutic intervention. Caspase 3 is not a novel target for ALS, as a previous clinical trial using minocycline 
was ineffective (Gordon et al., 2007), although perhaps this approach would be more efficacious in trials focused specifically on patients with ataxin 2 polyQ expansions. As is the hope for personalized medicine, stratifying patient populations based on specific genetic lesions could improve the outcome of clinical trials. Many groups are working on novel caspase inhibition methods for neurodegenerative disease, and perhaps more specific inhibitors could be applied to ALS patients with ataxin 2 polyQ expansions. Additionally, the polyQ-expanded ataxin 2 itself could represent a therapeutic target. We have previously reported the dramatic effect that ataxin 2 knockdown has on rescuing TDP-43 toxicity in the Drosophila nervous system (Elden et al., 2010). In patients with ataxin 2 polyQ expansions, knockdown of the mutant ataxin 2 might block the hyper-response to stress and perhaps protect motor neurons. Finally, we have identified a mechanistic difference between normal ataxin 2, ataxin 2 with ALS-associated intermediate-length polyQ expansions, and ataxin 2 with longer SCA2-associated polyQ expansions, which could begin to explain why different length polyQ expansions are associated with distinct, although perhaps overlapping, diseases (Fischbeck and Pulst, 2011).

\section{References}

Arai T, Hasegawa M, Akiyama H, Ikeda K, Nonaka T, Mori H, Mann D, Tsuchiya K, Yoshida M, Hashizume Y, Oda T (2006) TDP-43 is a component of ubiquitin-positive tau-negative inclusions in frontotemporal lobar degeneration and amyotrophic lateral sclerosis. Biochem Biophys Res Commun 351:602-611.

Barmada SJ, Skibinski G, Korb E, Rao EJ, Wu JY, Finkbeiner S (2010) Cytoplasmic mislocalization of TDP-43 is toxic to neurons and enhanced by a mutation associated with familial amyotrophic lateral sclerosis. J Neurosci 30:639-649.

Brady OA, Meng P, Zheng Y, Mao Y, Hu F (2011) Regulation of TDP-43 aggregation by phosphorylation and p62/SQSTM1. J Neurochem 116:248-259.

Buchan JR, Parker R (2009) Eukaryotic stress granules: the ins and outs of translation. Mol Cell 36:932-941.

Chen Y, Huang R, Yang Y, Chen K, Song W, Pan P, Li J, Shang HF (2011) Ataxin-2 intermediate-length polyglutamine: a possible risk factor for Chinese patients with amyotrophic lateral sclerosis. Neurobiol Aging 32:1925.e1-e5.

Cleveland DW, Rothstein JD (2001) From Charcot to Lou Gehrig: deciphering selective motor neuron death in ALS. Nat Rev Neurosci $2: 806-819$

Da Cruz S, Cleveland DW (2011) Understanding the role of TDP-43 and FUS/TLS in ALS and beyond. Curr Opin Neurobiol 21:904-919.

Daoud H, Belzil V, Martins S, Sabbagh M, Provencher P, Lacomblez L, Meininger V, Camu W, Dupré N, Dion PA, Rouleau GA (2011) Association of long ATXN2 CAG repeat sizes with increased risk of amyotrophic lateral sclerosis. Arch Neurol 68:739-742.

Dormann D, Capell A, Carlson AM, Shankaran SS, Rodde R, Neumann M, Kremmer E, Matsuwaki T, Yamanouchi K, Nishihara M, Haass C (2009) Proteolytic processing of TAR DNA binding protein- 43 by caspases produces $\mathrm{C}$-terminal fragments with disease defining properties independent of progranulin. J Neurochem 110:1082-1094.

Elden AC, Kim HJ, Hart MP, Chen-Plotkin AS, Johnson BS, Fang X, Armakola M, Geser F, Greene R, Lu MM, Padmanabhan A, Clay-Falcone D, McCluskey L, Elman L, Juhr D, Gruber PJ, Rüb U, Auburger G, Trojanowski JQ, Lee VM, et al. (2010) Ataxin-2 intermediate-length polyglutamine expansions are associated with increased risk for ALS. Nature 466:1069-1075.

Evert BO, Wüllner U, Klockgether T (2000) Cell death in polyglutamine diseases. Cell Tissue Res 301:189-204.

Fischbeck KH, Pulst SM (2011) Amyotrophic lateral sclerosis and spinocerebellar ataxia 2. Neurology 76:2050-2051.

Freibaum BD, Chitta RK, High AA, Taylor JP (2010) Global analysis of TDP-43 interacting proteins reveals strong association with RNA splicing and translation machinery. J Proteome Res 9:1104-1120.

Gispert S, Kurz A, Waibel S, Bauer P, Liepelt I, Geisen C, Gitler AD, Becker T,
Weber M, Berg D, Andersen PM, Krüger R, Riess O, Ludolph AC, Auburger G (2012) The modulation of Amyotrophic Lateral Sclerosis risk by ataxin-2 intermediate polyglutamine expansions is a specific effect. Neurobiol Dis 45:356-361.

Gordon PH, Moore DH, Miller RG, Florence JM, Verheijde JL, Doorish C, Hilton JF, Spitalny GM, MacArthur RB, Mitsumoto H, Neville HE, Boylan K, Mozaffar T, Belsh JM, Ravits J, Bedlack RS, Graves MC, McCluskey LF, Barohn RJ, Tandan R (2007) Efficacy of minocycline in patients with amyotrophic lateral sclerosis: a phase III randomised trial. Lancet Neurol 6:1045-1053.

Hart MP, Brettschneider J, Lee VM, Trojanowski JQ, Gitler AD (2012) Distinct TDP-43 pathology in ALS patients with ataxin 2 intermediate-length polyQ expansions. Acta Neuropathol. Advance online publication. Accessed April 21, 2012. doi:10.1007/s00401-012-0985-5.

Hasegawa M, Arai T, Nonaka T, Kametani F, Yoshida M, Hashizume Y, Beach TG, Buratti E, Baralle F, Morita M, Nakano I, Oda T, Tsuchiya K, Akiyama H (2008) Phosphorylated TDP-43 in frontotemporal lobar degeneration and amyotrophic lateral sclerosis. Ann Neurol 64:60-70.

Huynh DP, Figueroa K, Hoang N, Pulst SM (2000) Nuclear localization or inclusion body formation of ataxin-2 are not necessary for SCA2 pathogenesis in mouse or human. Nat Genet 26:44-50.

Huynh DP, Yang HT, Vakharia H, Nguyen D, Pulst SM (2003) Expansion of the polyQ repeat in ataxin-2 alters its Golgi localization, disrupts the Golgi complex and causes cell death. Hum Mol Genet 12:1485-1496.

Igaz LM, Kwong LK, Xu Y, Truax AC, Uryu K, Neumann M, Clark CM, Elman LB, Miller BL, Grossman M, McCluskey LF, Trojanowski JQ, Lee VM (2008) Enrichment of C-terminal fragments in TAR DNA-binding protein- 43 cytoplasmic inclusions in brain but not in spinal cord of frontotemporal lobar degeneration and amyotrophic lateral sclerosis. Am J Pathol 173:182-194.

Igaz LM, Kwong LK, Chen-Plotkin A, Winton MJ, Unger TL, Xu Y, Neumann M, Trojanowski JQ, Lee VM (2009) Expression of TDP-43 C-terminal fragments in vitro recapitulates pathological features of TDP-43 proteinopathies. J Biol Chem 284:8516-8524.

Imbert G, Saudou F, Yvert G, Devys D, Trottier Y, Garnier JM, Weber C, Mandel JL, Cancel G, Abbas N, Dürr A, Didierjean O, Stevanin G, Agid Y, Brice A (1996) Cloning of the gene for spinocerebellar ataxia 2 reveals a locus with high sensitivity to expanded CAG/glutamine repeats. Nat Genet 14:285-291.

Infante J, Berciano J, Volpini V, Corral J, Polo JM, Pascual J, Combarros O (2004) Spinocerebellar ataxia type 2 with Levodopa-responsive parkinsonism culminating in motor neuron disease. Mov Disord 19:848-852.

Inukai Y, Nonaka T, Arai T, Yoshida M, Hashizume Y, Beach TG, Buratti E, Baralle FE, Akiyama H, Hisanaga S, Hasegawa M (2008) Abnormal phosphorylation of Ser409/410 of TDP-43 in FTLD-U and ALS. FEBS Lett 582:2899-2904

Johnson BS, Snead D, Lee JJ, McCaffery JM, Shorter J, Gitler AD (2009) TDP-43 is intrinsically aggregation-prone, and amyotrophic lateral sclerosis-linked mutations accelerate aggregation and increase toxicity. J Biol Chem 284:20329-20339.

Jung J, Xu K, Lessing D, Bonini NM (2009) Preventing Ataxin-3 protein cleavage mitigates degeneration in a Drosophila model of SCA3. Hum Mol Genet 18:4843-4852.

Khong A, Jan E (2011) Modulation of stress granules and P bodies during dicistrovirus infection. J Virol 85:1439-1451.

Kraemer BC, Schuck T, Wheeler JM, Robinson LC, Trojanowski JQ, Lee VM, Schellenberg GD (2010) Loss of murine TDP-43 disrupts motor function and plays an essential role in embryogenesis. Acta Neuropathol 119:409-419.

Kwon S, Zhang Y, Matthias P (2007) The deacetylase HDAC6 is a novel critical component of stress granules involved in the stress response. Genes Dev 21:3381-3394.

Lagier-Tourenne C, Cleveland DW (2010) Neurodegeneration: an expansion in ALS genetics. Nature 466:1052-1053.

Lastres-Becker I, Rüb U, Auburger G (2008) Spinocerebellar ataxia 2 (SCA2). Cerebellum 7:115-124.

Lee T, Li YR, Ingre C, Weber M, Grehl T, Gredal O, de Carvalho M, Meyer T, Tysnes OB, Auburger G, Gispert S, Bonini NM, Andersen PM, Gitler AD (2011) Ataxin-2 intermediate-length polyglutamine expansions in European ALS patients. Hum Mol Genet 20:1697-1700.

Liachko NF, Guthrie CR, Kraemer BC (2010) Phosphorylation promotes 
neurotoxicity in a Caenorhabditis elegans model of TDP-43 proteinopathy. J Neurosci 30:16208-16219.

Ling SC, Albuquerque CP, Han JS, Lagier-Tourenne C, Tokunaga S, Zhou H, Cleveland DW (2010) ALS-associated mutations in TDP-43 increase its stability and promote TDP-43 complexes with FUS/TLS. Proc Natl Acad Sci U S A 107:13318-13323.

Liu-Yesucevitz L, Bilgutay A, Zhang YJ, Vanderwyde T, Citro A, Mehta T, Zaarur N, McKee A, Bowser R, Sherman M, Petrucelli L, Wolozin B (2010) Tar DNA binding protein-43 (TDP-43) associates with stress granules: analysis of cultured cells and pathological brain tissue. PLoS One 5:e13250.

Lorenzetti D, Bohlega S, Zoghbi HY (1997) The expansion of the CAG repeat in ataxin-2 is a frequent cause of autosomal dominant spinocerebellar ataxia. Neurology 49:1009-1013.

McDonald KK, Aulas A, Destroismaisons L, Pickles S, Beleac E, Camu W, Rouleau GA, Vande Velde C (2011) TAR DNA-binding protein 43 (TDP-43) regulates stress granule dynamics via differential regulation of G3BP and TIA-1. Hum Mol Genet 20:1400-1410.

Miguel L, Frébourg T, Campion D, Lecourtois M (2011) Both cytoplasmic and nuclear accumulations of the protein are neurotoxic in Drosophila models of TDP-43 proteinopathies. Neurobiol Dis 41:398-406.

Nanetti L, Fancellu R, Tomasello C, Gellera C, Pareyson D, Mariotti C (2009) Rare association of motor neuron disease and spinocerebellar ataxia type 2 (SCA2): a new case and review of the literature. J Neurol 256:1926-1928.

Neumann M, Sampathu DM, Kwong LK, Truax AC, Micsenyi MC, Chou TT, Bruce J, Schuck T, Grossman M, Clark CM, McCluskey LF, Miller BL, Masliah E, Mackenzie IR, Feldman H, Feiden W, Kretzschmar HA, Trojanowski JQ, Lee VM (2006) Ubiquitinated TDP-43 in frontotemporal lobar degeneration and amyotrophic lateral sclerosis. Science 314:130-133.

Neumann M, Kwong LK, Lee EB, Kremmer E, Flatley A, Xu Y, Forman MS, Troost D, Kretzschmar HA, Trojanowski JQ, Lee VM (2009) Phosphorylation of S409/410 of TDP-43 is a consistent feature in all sporadic and familial forms of TDP-43 proteinopathies. Acta Neuropathol 117:137-149.

Ng H, Pulst SM, Huynh DP (2007) Ataxin-2 mediated cell death is dependent on domains downstream of the polyQ repeat. Exp Neurol 208:207-215.

Nishimoto Y, Ito D, Yagi T, Nihei Y, Tsunoda Y, Suzuki N (2010) Characterization of alternative isoforms and inclusion body of the TAR DNAbinding protein-43. J Biol Chem 285:608-619.

Nonaka T, Arai T, Buratti E, Baralle FE, Akiyama H, Hasegawa M (2009) Phosphorylated and ubiquitinated TDP-43 pathological inclusions in ALS and FTLD-U are recapitulated in SH-SY5Y cells. FEBS Lett 583:394-400.

Nonhoff U, Ralser M, Welzel F, Piccini I, Balzereit D, Yaspo ML, Lehrach H, Krobitsch S (2007) Ataxin-2 interacts with the DEAD/H-box RNA helicase DDX6 and interferes with P-bodies and stress granules. Mol Biol Cell 18:1385-1396.

Ohn T, Kedersha N, Hickman T, Tisdale S, Anderson P (2008) A functional RNAi screen links O-GlcNAc modification of ribosomal proteins to stress granule and processing body assembly. Nat Cell Biol 10:1224-1231.

Orr HT, Zoghbi HY (2007) Trinucleotide repeat disorders. Annu Rev Neurosci 30:575-621.

Pesiridis GS, Tripathy K, Tanik S, Trojanowski JQ, Lee VM (2011) A "twohit" hypothesis for inclusion formation by C-terminal fragments of
TDP-43 protein linked to RNA depletion and impaired microtubuledependent transport. J Biol Chem 286:18845-18855.

Pulst SM, Nechiporuk A, Nechiporuk T, Gispert S, Chen XN, Lopes-Cendes I, Pearlman S, Starkman S, Orozco-Diaz G, Lunkes A, DeJong P, Rouleau GA, Auburger G, Korenberg JR, Figueroa C, Sahba S (1996) Moderate expansion of a normally biallelic trinucleotide repeat in spinocerebellar ataxia type 2. Nat Genet 14:269-276.

Ross CA (2002) Polyglutamine pathogenesis: emergence of unifying mechanisms for Huntington's disease and related disorders. Neuron $35: 819-822$

Ross OA, Rutherford NJ, Baker M, Soto-Ortolaza AI, Carrasquillo MM, DeJesus-Hernandez M, Adamson J, Li M, Volkening K, Finger E, Seeley WW, Hatanpaa KJ, Lomen-Hoerth C, Kertesz A, Bigio EH, Lippa C, Woodruff BK, Knopman DS, White CL 3rd, Van Gerpen JA, et al. (2011) Ataxin-2 repeat-length variation and neurodegeneration. Hum Mol Genet 20:3207-3212.

Sanpei K, Takano H, Igarashi S, Sato T, Oyake M, Sasaki H, Wakisaka A, Tashiro K, Ishida Y, Ikeuchi T, Koide R, Saito M, Sato A, Tanaka T, Hanyu S, Takiyama Y, Nishizawa M, Shimizu N, Nomura Y, Segawa M, et al. (1996) Identification of the spinocerebellar ataxia type 2 gene using a direct identification of repeat expansion and cloning technique, DIRECT. Nat Genet 14:277-284.

Sorarù G, Clementi M, Forzan M, Orsetti V, D’Ascenzo C, Querin G, Palmieri A, Ermani M, Angelini C, Pegoraro E (2011) ALS risk but not phenotype is affected by ataxin-2 intermediate length polyglutamine expansion. Neurology 76:2030-2031.

Swisher KD, Parker R (2010) Localization to, and effects of Pbp1, Pbp4, Lsm12, Dhh1, and Pab1 on stress granules in Saccharomyces cerevisiae. PLoS One 5:e10006.

Thomas MG, Loschi M, Desbats MA, Boccaccio GL (2011) RNA granules: the good, the bad and the ugly. Cell Signal 23:324-334.

Tsai NP, Ho PC, Wei LN (2008) Regulation of stress granule dynamics by Grb7 and FAK signalling pathway. EMBO J 27:715-726.

Van Damme P, Veldink JH, van Blitterswijk M, Corveleyn A, van Vught PW, Thijs V, Dubois B, Matthijs G, van den Berg LH, Robberecht W (2011) Expanded ATXN2 CAG repeat size in ALS identifies genetic overlap between ALS and SCA2. Neurology 76:2066-2072.

Van Langenhove T, van der Zee J, Engelborghs S, Vandenberghe R, Santens P, Van den Broeck M, Mattheijssens M, Peeters K, Nuytten D, Cras P, De Deyn PP, De Jonghe P, Cruts M, Van Broeckhoven C (2012) Ataxin-2 polyQ expansions in FTLD-ALS spectrum disorders in Flanders-Belgian cohorts. Neurobiol Aging 33:1004.e17-20.

White JP, Cardenas AM, Marissen WE, Lloyd RE (2007) Inhibition of cytoplasmic mRNA stress granule formation by a viral proteinase. Cell Host Microbe 2:295-305.

Wiedemeyer R, Westermann F, Wittke I, Nowock J, Schwab M (2003) Ataxin-2 promotes apoptosis of human neuroblastoma cells. Oncogene 22:401-411.

Young JE, Gouw L, Propp S, Sopher BL, Taylor J, Lin A, Hermel E, Logvinova A, Chen SF, Chen S, Bredesen DE, Truant R, Ptacek LJ, La Spada AR, Ellerby LM (2007) Proteolytic cleavage of ataxin-7 by caspase-7 modulates cellular toxicity and transcriptional dysregulation. J Biol Chem 282:30150-30160.

Zhang YJ, Xu YF, Dickey CA, Buratti E, Baralle F, Bailey R, Pickering-Brown S, Dickson D, Petrucelli L (2007) Progranulin mediates caspasedependent cleavage of TAR DNA binding protein-43. J Neurosci 27: $10530-10534$. 